\title{
Nanopartículas catalisadoras suportadas por materiais cerâmicos
}

\section{(Catalytic nanoparticles supported by ceramic materials)}

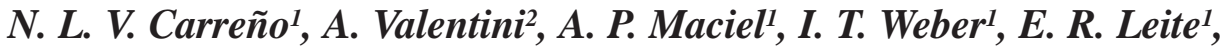 \\ L. F. D. Probst ${ }^{2}$, E. Longo ${ }^{1}$ \\ ${ }^{1}$ Centro Multidisciplinar de Desenvolvimento de Materiais Cerâmicos (CMDMC), \\ Universidade Federal de S. Carlos, C.P. 676, 13560-905, S. Carlos, SP \\ ${ }^{2}$ LABOCATH, Departamento de Química \\ Universidade Federal de Santa Catarina \\ C.P. 476, 88040-900 Florianópolis, SC \\ dels@power.ufscar.br
}

\begin{abstract}
Resumo
Neste trabalho são apresentados os procedimentos de preparação de materiais cerâmicos de $\mathrm{SiO}_{2}, \mathrm{SnO}_{2}$ e $\mathrm{Al}_{2} \mathrm{O}_{3}$ e, também, suas propriedades catalíticas nas reações de reforma do metano e do metanol. As análises dos resíduos de carbono, após testes catalíticos, sugerem que a modificação estrutural dos catalisadores pode minimizar os efeitos de sua desativação. Palavras-chave: Nanopartículas, catálise.
\end{abstract}

\begin{abstract}
This work presents the procedures for preparing $\mathrm{SiO}_{2}, \mathrm{SnO}_{2}$ and $\mathrm{Al}_{2} \mathrm{O}_{3}$ ceramic materials and also their catalytic properties for the reforming reactions of methane and methanol. The analyses of the carbonaceous residues suggest that the structural modification of the catalyst can minimize the deactivation effect upon them.
\end{abstract}

Keywords: Nanoparticles, catalysis

\section{INTRODUÇÃO}

O desenvolvimento da catálise como ciência autônoma passou por diversas fases, desde que Berzelius em 1836 criou o termo "catálise", para descrever processos que eram ativados por pequenas quantidades de substâncias, dando origem a transformações químicas sem serem consumidas. Essas substâncias que permitem que as transformações de matérias primas, num determinado processo químico, sejam rápidas, foram denominadas catalisadores. Como definição geral temse que o catalisador aumenta a velocidade de uma reação sem ser consumido no processo (IUPAC, 1976).

A preparação de catalisadores foi durante muitos anos considerada uma arte restrita aos alquimistas. Contudo, a partir do século passado, as bases teóricas da preparação dos catalisadores têm sido estudadas e desenvolvidas, podendo-se afirmar que a preparação de catalisadores é hoje um ramo da ciência. Dois exemplos podem ilustrar esta afirmação: a síntese das zeólitas de estruturas cristalinas com poros de dimensões inferiores a $5 \mathrm{~nm}$ e a dispersão de baixos teores de metais em escala atômica em suportes cerâmicos [1].

As principais propriedades dos catalisadores (atividade, seletividade, estabilidade, resistência mecânica e condutividade térmica) estão intimamente relacionadas a sua composição e tecnologia de preparação [1,2]. Essas propriedades dependem, principalmente, da seleção entre os diversos materiais e dos métodos de preparação. Por exemplo, na preparação de um catalisador de níquel suportado, para a hidrogenação de benzeno, podem ser selecionados diferentes materiais de partida de níquel. Este catalisador pode envolver nitratos, cloretos, óxidos, entre outros, e para suporte da fase metálica (Ni) podem ser usados sílica, alumina, óxido de magnésio, óxido de titânio, zeólitas, e demais materiais refratários. Dentro dos métodos de preparação freqüentemente usados para obter esses catalisadores estão os métodos: impregnação e sol gel [2].

Muitos catalisadores usados em processos industriais são robustos sólidos inorgânicos, usualmente óxidos de metais ou estruturas suportadas, os quais têm sido preparados por impregnação úmida [1], método desenvolvido em 1920. Este processo não permite o essencial controle dos sítios metálicos em geral, obtendo-se assim catalisadores com superfície não uniforme. Este fato dificulta a caracterização dos mesmos, e na maioria dos casos a análise da relação entre estrutura e desempenho é fracamente definida. Como resultado, os mecanismos catalíticos são entendidos somente a nível macroscópico. Portanto, o progresso da eficiência da catálise não tem sido cientificamente alcançada para maioria dos sistemas a nível molecular [3].

Contudo, catalisadores contendo metais preparados por reações entre apropriados complexos orgânicos e inorgânicos e superfícies de óxidos inorgânicos, os quais possuem química e estruturalmente superfícies controladas, também podem 
contribuir para elucidar os mecanismos catalíticos envolvendo mudanças dinâmicas dos sítios ativos numa escala molecular [3].

\section{Processos catalíticos}

Os esforços realizados nas pesquisas na área de catálise buscam em sua maioria a simplificação dos processos ou mudança de sistemas, no qual a seletividade ou o rendimento é baixo ou o gasto de energia é muito elevado. Portanto, o desenvolvimento de processos que possibilitem as operações em menores temperaturas e pressões é atraente e compensador [4]. Sabe-se que o desenvolvimento de um catalisador que apresente bons resultados num dado processo industrial requer um elevado investimento, sendo na maioria das vezes, o estágio exploratório, conduzido em instituições de ensino, as quais preparam e testam os catalisadores em micro escala, depois de definida a reação química.

O processamento de catalisadores com "clusters" metálicos, suportados em superfícies ativas, podem guiar frequientemente o surgimento de diferentes tipos de reações químicas nos processos catalíticos, decorrentes das interações entre os sítios ativos metálicos e os suportes do catalisador. De fato, muitos óxidos inorgânicos usados como suporte possuem sítios ativos: ácidos/básicos de grupos hidróxilas ou centros ácidos/básicos

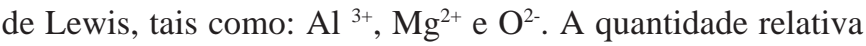
dos sítios de Brønsted ou Lewis, e suas características ácido/ base estão relacionadas com a natureza dos óxidos e grau de hidratação superficial. Em adição, a interação simples entre os sítios ácidos/básicos e os "clusters" metálicos, também, podem ser observados processos de ataque nucleofílicos, por parte de $\mathrm{CO}$ coordenado e adição oxidativa de grupos $\mathrm{OH}^{-}$nas ligações metal-metal, os mesmos podem eventualmente influenciar o processo de quimissorção na superfície reacional. A superfície, de óxidos inorgânicos, pode consequientemente ser representada como um ligante multidentado. Este dualismo da superfície reativa pode ser interpretado como um inerente "solvente" ou um "sólido-ligante" de elevada atividade, reconhecido como uma etapa determinante nas propriedades de um suporte catalítico $[1,5]$.

Suportes a base óxido de zircônio, titânio, cério, alumínio, sílica e nióbio entre outros, são freqüentemente usados como suportes de metais com fins catalíticos. Os mesmos possuem geralmente características importantes que devem ser levadas em consideração, nos diversos processos catalíticos, tais como: atividade, seletividade, estabilidade, resistência mecânica e condutividade térmica [1, 6-9].

As reações de decomposição do metanol, reforma do metano e do gás natural, são reações de elevado interesse para obtenção de fontes de energia alternativa (gás de sínteses), que tem chamado sempre atenção da comunidade científica. O processo inovador desenvolvido por Fischer e Tropsch, no uso de gás de síntese para a obtenção de produtos químicos de elevado valor comercial e industrial foi inventado na década de vinte [10]. No entanto, ainda hoje requer pesquisa na obtenção de processos e catalisadores que sejam mais seletivos e de menor consumo energético para dado objetivo. Catalisadores para aplicações em tal síntese usualmente contêm metal do Grupo VIII, como sítio ativo. Em particular, ferro, cobalto, níquel e rutênio têm sido largamente utilizados. Cobalto e rutênio são tidos como os mais adequados para o processo, no qual o gás de síntese é convertido, com elevada seletividade, em hidrocarbonetos possuindo cinco ou mais átomos de carbono.

Neste trabalho é apresentada a síntese de nanopartículas de $\mathrm{Ni}$ metálico imersas em uma matriz cerâmica de $\mathrm{SiO}_{2}$ mesoporosa. Os efeitos microestruturais obtidos para o dióxido de estanho nanoestruturado dopado com terras raras, ambos preparados pelo método dos precursores poliméricos e as modificações microestruturais promovidas pela adição de $\mathrm{CeO}_{2}$ no catalisador $\mathrm{Ni} / \gamma-\mathrm{Al}_{2} \mathrm{O}_{3}$, estes últimos obtidos pelo método de impregnação úmida.

Análises das propriedades catalíticas destes materiais na reação de reforma do metanol e do metano. Como também, o estudo dos processos de desativações catalíticas desses materiais após os processos catalíticos.

\section{EXPERIMENTAL}

\section{Precursores poliméricos}

Um método que vem sendo bastante utilizado para obtenção de nanopartículas de dióxido de estanho, em especial para $\mathrm{SnO}_{2}$ dopado, é o dos precursores poliméricos, baseado no método Pechini [11]. Este consiste na formação de quelatos entre os cátions metálicos (dissolvidos em meio aquoso) com ácido carboxílico (geralmente o ácido cítrico) e posterior polimerização utilizando uma reação de poliesterificação com poliálcool (preferencialmente etilenoglicol).

A reação de condensação (ácido carboxílico + poliálcool) ocorre em temperaturas moderadas $\left(\mathrm{T}<100^{\circ} \mathrm{C}\right)$, em recipiente aberto sob agitação. Durante o aquecimento ocorre a reação de poliesterificação, resultando uma "resina" polimérica viscosa, solúvel em água. Após esse estágio, o poliéster é calcinado à temperatura de aproximadamente $300{ }^{\circ} \mathrm{C}$, para pirólise do polímero e conseqüente eliminação do material orgânico na forma de $\mathrm{CO}_{2}$ e água. $\mathrm{O}$ material obtido é desagregado, e calcinado novamente, para eliminação do material orgânico residual. Neste estágio o material está pronto para a obtenção da fase e da cristalinidade desejada por intermédio de tratamento térmico.

\section{Obtenção dos precursores poliméricos da matriz de sílica e níquel}

O citrato metálico foi obtido por intermédio da simples dissolução de 0,672 moles de ácido cítrico (Merck) em 100 $\mathrm{mL}$ de etanol (Synth) sob agitação mecânica. Após a completa dissolução do ácido cítrico, foram adicionados $50 \mathrm{~mL}$ de tetraetoxisilano (TEOS) da Aldrich, seguido do acréscimo de nitrato de níquel hexahidratado (Merck). Para a obtenção da resina polimerizada foram adicionados $62,17 \mathrm{~mL}$ de etilenoglicol (Aldrich).

As diferentes amostras foram preparadas seguindo-se o procedimento descrito acima, variando-se a estequiometria entre TEOS e nitrato de níquel hexaidratado (conforme o percentual de níquel desejado). A relação molar de 3/1 entre ácido cítrico e TEOS e a relação mássica de 6/4 entre ácido 
cítrico e etilenoglicol foram mantidas constantes. As amostras sintetizadas foram designadas como $x-\mathrm{SiO}_{2}$, em que o $x$ corresponde à concentração de $\mathrm{Ni}$ em massa por grama de amostra.

Nos tratamentos térmicos dos precursores poliméricos, as resinas foram ligeiramente aquecidas numa chapa de aquecimento, com a finalidade de aumentar a viscosidade das mesmas. Em seguida, foram levadas a uma mufla termoprogramada na temperatura de $225^{\circ} \mathrm{C}$, por um período de 4 horas. O polímero pirolisado (“puff”), material obtido após esse tratamento das resinas, foi desagregado por moagem num moinho tipo atritor (Szegvari Attritor System 01HD), para a obtenção de um pó com granulometria menor que 300 mesh. Em continuação, o material foi calcinado em um forno lacrado EDG, tipo tubo, e tratado termicamente a diferentes temperaturas entre $300{ }^{\circ} \mathrm{C}$ e $800{ }^{\circ} \mathrm{C}$, com tempos variáveis e com taxa de aquecimento de $12^{\circ} \mathrm{C} / \mathrm{min}$ sob atmosfera protetora de $\mathrm{N}_{2}$, com fluxo de $1 \mathrm{~cm}^{3} / \mathrm{min}$, sendo posteriormente resfriado até $50{ }^{\circ} \mathrm{C}$ a uma taxa de $8{ }^{\circ} \mathrm{C} / \mathrm{min}$.

Preparação das amostras impregnadas do sistema $\mathrm{Ni} / \gamma-\mathrm{Al}_{2} \mathrm{O}_{3}-\mathrm{CeO}_{2}$

Foram preparadas diferentes amostras compostas de $\gamma-\mathrm{Al}_{2} \mathrm{O}_{3}$ (AL-3996R, $200 \mathrm{~m}^{2} / \mathrm{g}$, Engelhard Exceptional Technologies) contendo $(5,10,15$ e 20\%) em massa de óxido de cério, por intermédio de impregnação úmida de $\mathrm{Ce}\left(\mathrm{NO}_{3}\right)_{3}$ (Aldrich, $99,99 \%$ ) sobre a $\gamma-\mathrm{Al}_{2} \mathrm{O}_{3}$, seguida de secagem e calcinação (450 ${ }^{\circ} \mathrm{C}$ ). Após a preparação das mesmas, foi realizada a deposição do metal $\left(\mathrm{Ni}\right.$ ) nas diferentes misturas, $\gamma-\mathrm{Al}_{2} \mathrm{O}_{3}-\mathrm{CeO}_{2}$ (doravante denominadas $\mathrm{Ni} / \mathrm{AlCe}-x, \operatorname{com} x$ sendo igual a porcentagem de $\mathrm{CeO}_{2}$ no sistema) e em $\gamma-\mathrm{Al}_{2} \mathrm{O}_{3}$ e $\mathrm{CeO}_{2}$ (Riedel-de Haen, 99\%), por intermédio do método de impregnação úmida com nitrato de níquel (Fluka, 98\%, teor de sulfato $\leq 0,005 \%$ ), seguida de secagem em estufa durante 24 horas a $100{ }^{\circ} \mathrm{C}$, e calcinação em $650{ }^{\circ} \mathrm{C}$ por 3 horas.

\section{Instrumentação}

Para a caracterização por difração de raios X foi utilizado um difratômetro Siemens D5000, usando a radiação K $\alpha$ do $\mathrm{Cu}$ e monocromador de grafite. A área superficial específica foi obtida utilizando-se o equipamento ASAP 2000 da Micromeritics. O teor metálico nas amostras foi determinado por espectrometria de absorção atômica de chama (FAAS), num equipamento Varian AA-800, equipado com uma lâmpada de cátodo oco operando a $351,5 \mathrm{~nm}$ e corrente de $4 \mathrm{~mA}$, resolução do monocromador de 0,2 $\mathrm{nm}$ e chama ar-acetileno em condição oxidante. As análises elementares foram realizadas no equipamento CHNS-O FISONS EA 1108.

Para a caracterização microestrutural foi usado o microscópio eletrônico de transmissão (CM200 Philips Holland, $200 \mathrm{kV}$ ).

\section{Reforma do metanol}

A análise do comportamento catalítico (amostras com óxido de estanho) na reação de decomposição do metanol foi efetuada em um microreator de aço inoxidável sob pressão atmosférica. A mistura reacional era composta por ar e metanol (6,3 mol\%), sob fluxo de $45 \mathrm{~cm}^{3} / \mathrm{min}$. Os produtos foram analisados em um cromatógrafo gasoso SHIMADZU GC-8A, coluna Porapak-Q, equipado com detetor de condutividade térmica (TCD).

\section{Reforma do metano}

A avaliação dos catalisadores foi realizada em teste microcatalítico, à pressão atmosférica em $625^{\circ} \mathrm{C}$, em fase gasosa. A mistura reacional foi composta de $\mathrm{N}_{2}: \mathrm{CH}_{4}: \mathrm{CO}_{2}$, na proporção de 5:1:1. A massa de catalisador utilizada foi de 50 mg, com ativação em $650{ }^{\circ} \mathrm{C}$ durante 1 hora sob fluxo de $\mathrm{H}_{2}$. Os produtos da reação foram analisados por intermédio de cromatografia gasosa (Shimadzu GC-8A, coluna Porapak Q e PM-5A, detetor TCD).

\section{RESULTADOS}

Nanopartículas de Ni dispersas em sílica amorfa e aplicação catalítica na decomposição catalítica de metanol

A geração de Ni metálico no processo de calcinação das amostras do precursor $\mathrm{Ni} / \mathrm{SiO}_{2}$ pode ser comprovada pelos

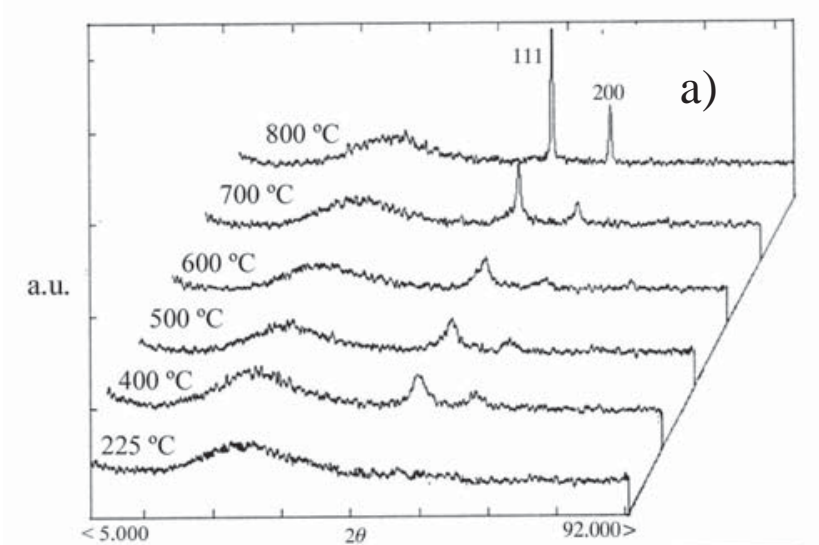

b)

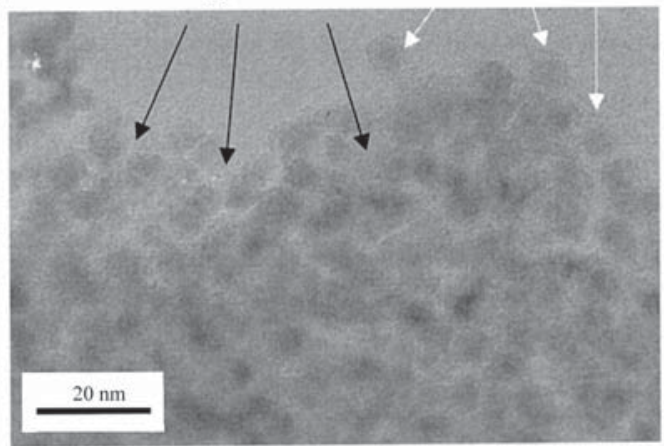

Figura 1: a) Difratogramas de raios $\mathrm{X}$ das nanopartículas de $\mathrm{Ni}$ dispersos em sílica amorfa, obtidos em diferentes temperaturas, da amostra $12,5-\mathrm{SiO}_{2}$; b) Imagens de campo claro de MET, da amostra tratadas a $500{ }^{\circ} \mathrm{C} / 2 \mathrm{~h}$.

[Figure 1: a) XRD patterns of the Ni nanoparticles dispersed in amorphous silica, otained at different pyrolysis temperatures for the 12,5-SiO ${ }_{2}$ sample; b) BF-TEM image of the 12.5- $\mathrm{SiO}_{2}$ nanocomposite sample heat-treated at $\left.500{ }^{\circ} \mathrm{C}.\right]$ 
resultados de difração de raios $\mathrm{X}$, obtidos após o tratamento térmico das amostras em atmosfera de $\mathrm{N}_{2}$, sem a necessidade de uma atmosfera redutora $\left(\mathrm{H}_{2}\right)$. Os difratogramas típicos das nanopartículas de $\mathrm{Ni}$ ( $2 \theta$ igual a 44,5, plano cristalino 111 e 51,8 plano cristalino 200) [12], dispersas em uma matriz de sílica amorfa, tratadas em temperaturas que variaram de 225 a $800^{\circ} \mathrm{C}$, durante 2 horas. Estes difratogramas apresentaram uma fase cristalina correspondente ao níquel metálico, e uma fase amorfa da matriz de sílica (Fig. 1a). O tamanho médio do cristalito de Ni nas amostras obtidas, após o tratamento térmico, em atmosfera inerte $\left(\mathrm{N}_{2}\right)$ foram caracterizados por difração de raios $\mathrm{X}$, utilizando-se a largura a meia altura (FWHM) dos difratogramas das amostras (DRX), por meio da equação de Scherrer [12].

As amostras tratadas em $500{ }^{\circ} \mathrm{C}$, por duas horas, apresentaram tamanhos médio de cristalitos de Ni próximo de $4 \mathrm{~nm}$. A Fig. $2 \mathrm{~b}$ ilustra as imagens de campo claro da microscopia eletrônica de transmissão (MET) da amostra contendo $23 \%$ em peso de níquel termicamente tratada em atmosfera inerte. Os pontos escuros dispersos homogeneamente no interior de uma estrutura tipicamente amorfa (sílica), observados na imagem de MET correspondem as nanopartículas de Ni.

A análise de adsorção-dessorção de $\mathrm{N}_{2}$ sugerem microporosidade [13], em concentrações acima de 5\% em peso de níquel, as curvas de adsorção-dessorção de $\mathrm{N}_{2}$ indicaram uma mesoporosidade no material. As curvas de distribuição de tamanhos de poros obtidas pelo método de $\mathrm{BJH}$ [13] para as amostras $5-\mathrm{SiO}_{2}$ e $47-\mathrm{SiO}_{2}$, termicamente tratadas a $500{ }^{\circ} \mathrm{C}$, por 2 horas, são apresentadas na Fig. 2. A Fig. 2a ilustra que há uma estreita faixa de distribuição de poros (30 ̊) para a amostra $5-\mathrm{SiO}_{2}$. Com incremento da concentração de $\mathrm{Ni}$ há uma distribuição muito clara bi-modal do tamanho dos poros na matriz amorfa, Figs. 2 b e $2 \mathrm{c}$ das amostras $12,5-\mathrm{SiO}_{2}$ e $47-\mathrm{SiO}_{2}$, respectivamente.

A amostra $\left(5-\mathrm{SiO}_{2}\right)$ possui uma área superficial específica $\left(\mathrm{S}_{\mathrm{BET}}\right)$ de $280 \mathrm{~m}^{2} / \mathrm{g}$, enquanto que o material com maior concentração de $\mathrm{Ni}\left(12,5-\mathrm{SiO}_{2}\right.$ e 47- $\left.\mathrm{SiO}_{2}\right)$ apresentaram áreas superficiais específicas menores $\left(\mathrm{S}_{\mathrm{BET}}\right)$ de $247 \mathrm{~m}^{2} / \mathrm{g}$ e $202 \mathrm{~m}^{2} / \mathrm{g}$, respectivamente. Fato que pode ser explicado como resultado do aumento da concentração de níquel e consequentemente preenchimentos dos poros da matriz amorfa. A área metálica $\left(\mathrm{S}_{\mathrm{M}}\right)$ determinada foi $14,2 \mathrm{~m}^{2} / \mathrm{g}, 5,2 \mathrm{~m}^{2} / \mathrm{g}, 1,8 \mathrm{~m}^{2} / \mathrm{g}$. respectivamente para as amostras $\left(47-\mathrm{SiO}_{2}\right.$ e $\left.12,5-\mathrm{SiO}_{2}, 5-\mathrm{SiO}_{2}\right)$.

A avaliação da atividade catalítica das amostras nanoestruturadas foi realizada por intermédio da reação de decomposição do metanol. Para estes ensaios foram utilizadas as amostras 5- $\mathrm{SiO}_{2}, 12,5-\mathrm{SiO}_{2}$ e $47-\mathrm{SiO}_{2}$. As mesmas foram comparadas com catalisadores preparados pelos métodos convencionais (impregnação úmida), os dados obtidos são apresentados na Tabela I.

Comportamento catalítico diferenciado entre as amostras

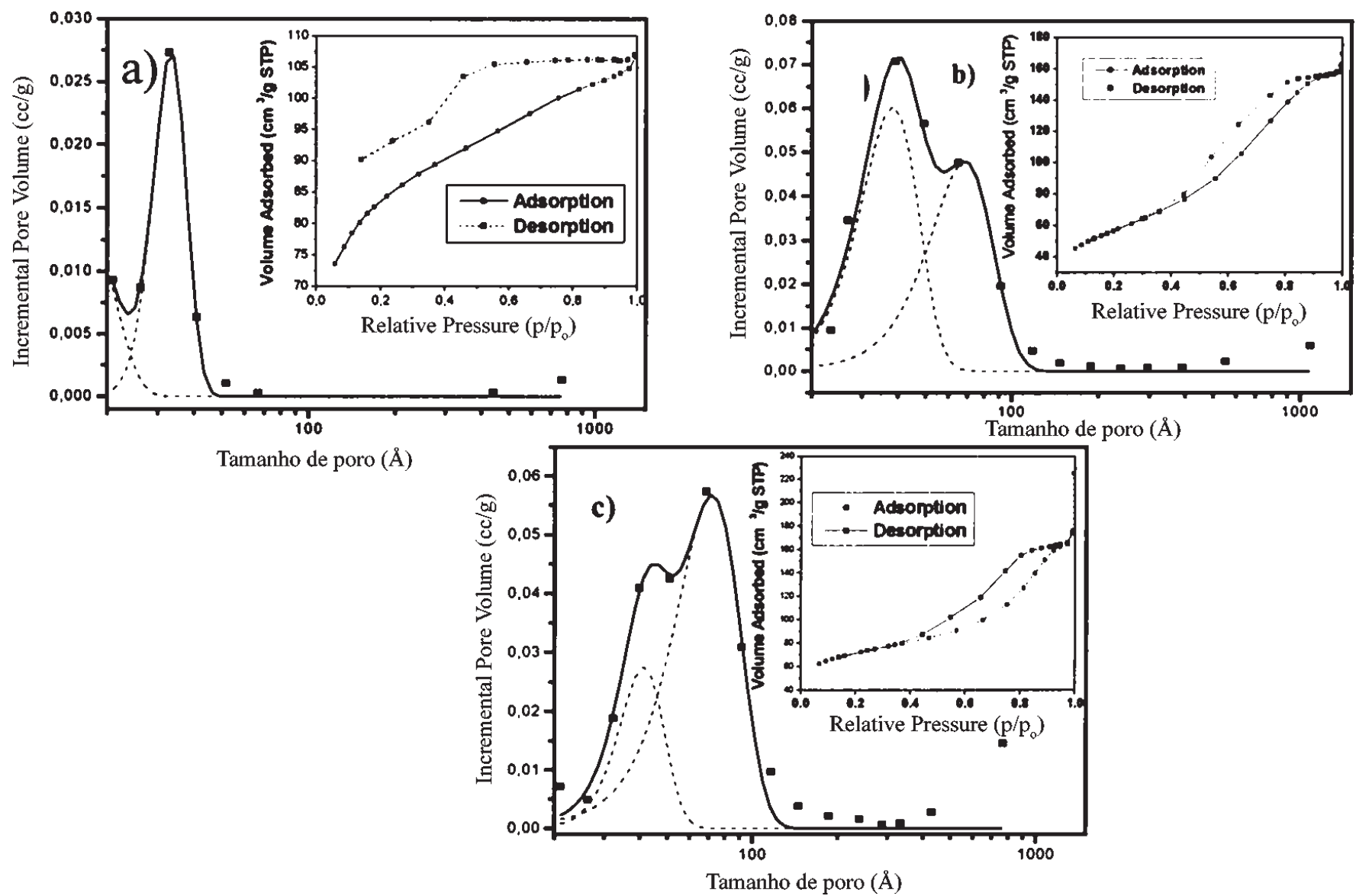

Figura 2: Distribuição do tamanho de poros das amostras tratadas a $500{ }^{\circ} \mathrm{C}$ durante $2 \mathrm{~h}$ e curva de Adsorção-dessorção de $\mathrm{N}_{2}$ (figura inserida) para as amostras tratadas a $500{ }^{\circ} \mathrm{C}$ durante $2 \mathrm{~h}$ : a) $5 \%$ de $\mathrm{Ni}-\mathrm{SiO}_{2}$; b) $12,5 \%$ de $\mathrm{Ni}-\mathrm{SiO}_{2}$ e c) $47 \%$ de $\mathrm{Ni}-\mathrm{SiO}_{2}$.

[Figure 2: Pore size distribution and $\mathrm{N}_{2}$ adsorption-desorption isothermal plots (inset) for samples heat treated at $500{ }^{\circ} \mathrm{C}$ during $2 \mathrm{~h}$; a) $5 \%$ $\mathrm{Ni}-\mathrm{SiO}_{2}$; b) $12,5 \% \mathrm{Ni}-\mathrm{SiO}_{2}$ and c) $47 \% \mathrm{Ni}-\mathrm{SiO}_{2}$.] 
Tabela I - Conversão de metanol na presença do catalisadores de níquel efeito comparativo a $240{ }^{\circ} \mathrm{C}$. Amostras tratadas a $500{ }^{\circ} \mathrm{C}$ durante $2 \mathrm{~h}$.

[Table I - Methanol conversion over nickel catalysts: comparative performance at $240^{\circ} \mathrm{C}$. Sample heat treated at $500{ }^{\circ} \mathrm{C}$ during $2 \mathrm{~h}$.]

\begin{tabular}{lcccc}
\hline Catalisador & \multicolumn{2}{c}{ Conversão / \% } & \multicolumn{2}{c}{$\mathbf{C H}_{\mathbf{4}}$ Seletividade / \% } \\
\hline 5-Ni/SiO & $\mathbf{4 0}(\mathbf{c c} / \mathbf{m i n})$ & $\mathbf{6 0}(\mathbf{c c} / \mathbf{m i n})$ & $\mathbf{4 0}(\mathbf{c c} / \mathbf{m i n})$ & $\mathbf{6 0}(\mathbf{c c} / \mathbf{m i n})$ \\
\hline 13-Ni/SiO & 71,8 & 66,6 & 0,4 & 0,3 \\
\hline $46-\mathrm{Ni} / \mathrm{SiO}_{2}$ & 82,5 & 78,3 & 0,8 & 0,5 \\
\hline 5-Ni:Si* & 86,4 & 79,3 & 1,8 & 1,0 \\
\hline 12,5-Ni:Si* & 15,4 & 8,0 & 0,0 & 0,0 \\
\hline 47-Ni:Si* & 82,5 & 69,8 & 2,3 & 1,5 \\
\hline
\end{tabular}

Massa de catalisador $=53 \mathrm{mg}, 40$ e $60 \mathrm{cc} / \mathrm{min}=$ fluxo total $\left(\mathrm{Ar}+\mathrm{CH}_{3} \mathrm{OH}\right)$

* preparados por impregnação úmida

a.u.
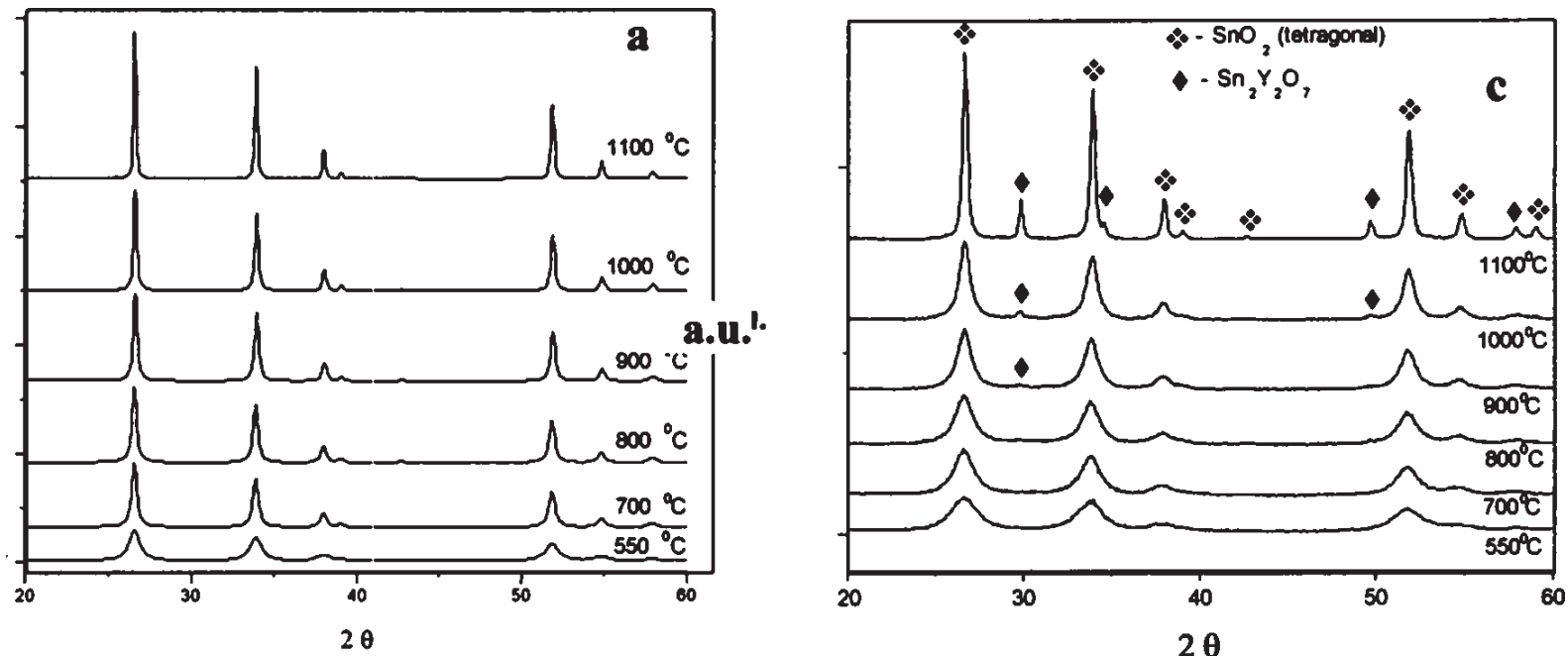

a.u.
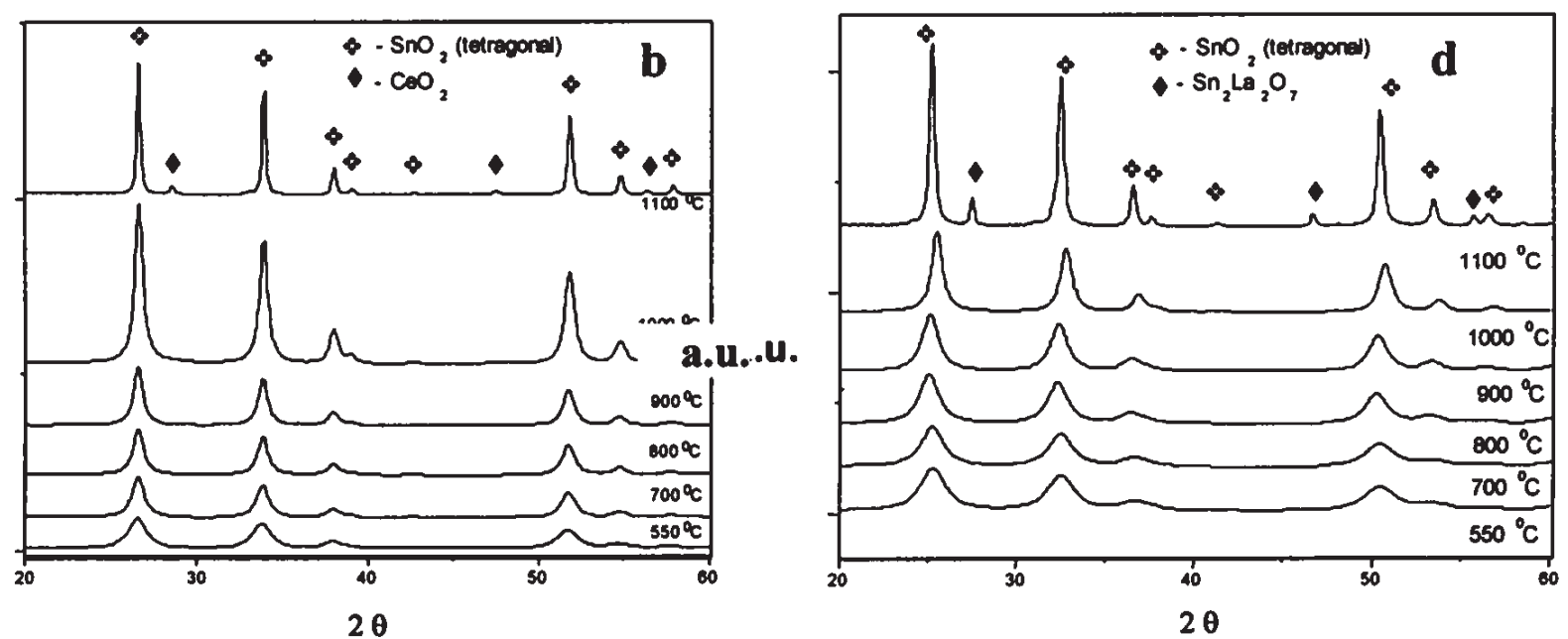

Figura 3: Difratogramas de raios $\mathrm{X}$ das nanopartículas de $\mathrm{SnO}_{2}$ : a) não dopadas; b) dopadas com 5\% de Ce; c) dopadas com 5\% de $\mathrm{Y}$; d) dopadas com $5 \%$ de La.

[Figure 3: XRD patterns of the nanoparticles of $\mathrm{SnO}_{2}:$ a) undoped; b) $\mathrm{SnO}_{2}$ doped with 5 mol\% of $\mathrm{Ce}$; c) $\mathrm{SnO}_{2}$ doped with $5 \mathrm{~mol} \%$ of $\mathrm{Y}$; d) $\mathrm{SnO}_{2}$ doped with 5 mol\% of La.] 
preparadas por distintos métodos podem estar relacionados com as contribuições de possíveis problemas difusionais do reagente até os sítios metálicos, devido à estreita faixa de distribuição de poros apresentada por esta amostra.

\section{Nanoestrutura de $\mathrm{SnO}_{2}$ e seus efeitos na decomposição do metanol}

A difração de raios $\mathrm{X}$ foi utilizada para caracterização das fases existentes nos materiais obtidos, nanopartículas de $\mathrm{SnO}_{2}$ não dopado (puro) e dopado com 5\% em mol de Ce, Y e La. As amostras foram tratadas termicamente durante duas horas nas seguintes temperaturas: $550{ }^{\circ} \mathrm{C}, 700{ }^{\circ} \mathrm{C}, 800{ }^{\circ} \mathrm{C}, 900{ }^{\circ} \mathrm{C}$, $1000{ }^{\circ} \mathrm{C}$ e $1100{ }^{\circ} \mathrm{C}$.

Os resultados de difração de raios X para as amostras de $\mathrm{SnO}_{2}$ não dopadas, calcinadas no intervalo de temperatura de $550{ }^{\circ} \mathrm{C}$ a $1100{ }^{\circ} \mathrm{C}$, Fig. 3a, indicam apenas a fase cassiterita (tetragonal).

Para as amostras dopadas com 5\% de Ce, a difração de raios X, Fig. 3b, ilustra apenas a fase cassiterita (tetragonal), indicando a formação de solução sólida para as amostras tratadas até $1000{ }^{\circ} \mathrm{C}$. Para a amostra calcinada em $1100{ }^{\circ} \mathrm{C}$ por 2 horas, observou-se a segregação de $\mathrm{CeO}_{2}$.

A análise da amostra dopada com $5 \%$ de ítrio por difração de raios $\mathrm{X}$, Fig. 3c, ilustra uma única fase até $800{ }^{\circ} \mathrm{C}$, observando-se apenas a fase cassiterita (tetragonal), indicando a formação de solução sólida. A partir de $900{ }^{\circ} \mathrm{C}$ ocorre a segregação de uma segunda fase identificada como $\mathrm{Sn}_{2} \mathrm{Y}_{2} \mathrm{O}_{7}$.

Na Fig. 3d estão expostos os padrões de difração de raios $\mathrm{X}$ para as amostras dopadas com 5\% de lantânio. Pode-se observar que as amostras são monofásicas quando tratados até $1000{ }^{\circ} \mathrm{C}$, como no caso do $\mathrm{SnO}_{2}$ dopado com Ce, observandose apenas a fase cassiterita (tetragonal), indicando a formação

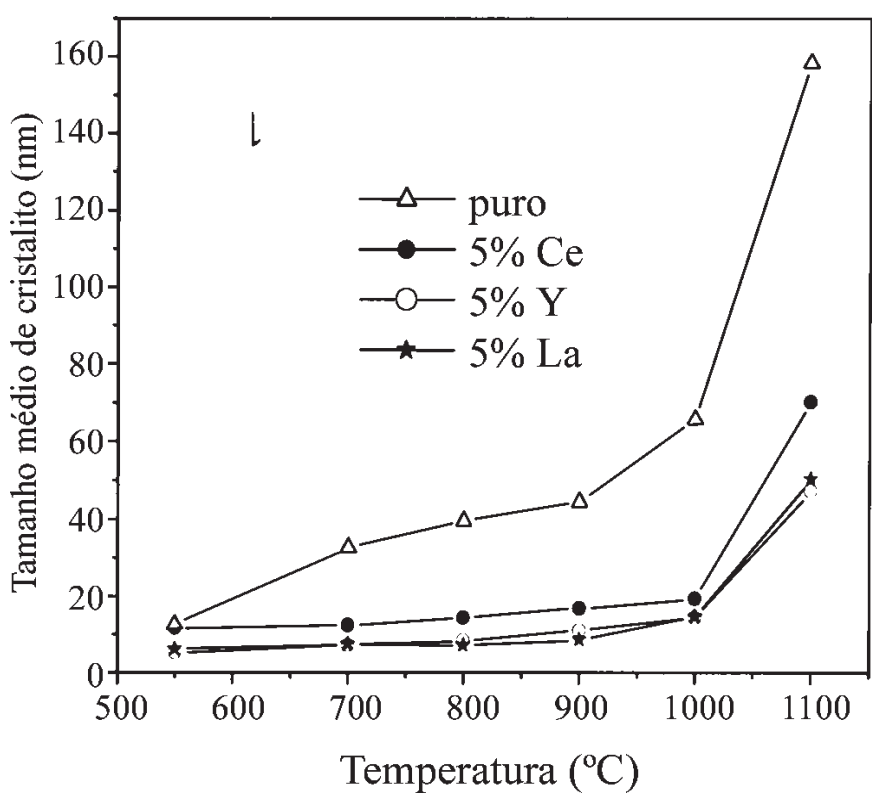

Figura 4: a) Tamanho médio de cristalito das amostras em função do tratamento térmico.

[Figure 4: Mean crystallite size of sample as a function of the heattreatment temperature.]

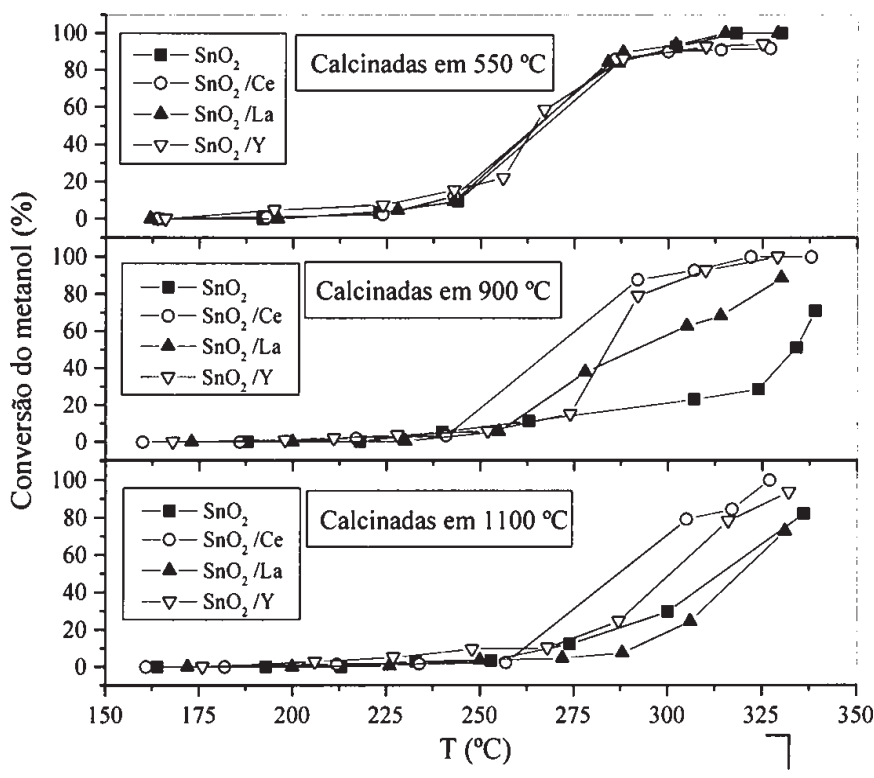

Figura 5: Conversão do metanol em função da temperatura reacional. [Figure 5: Methanol conversion as a function of the reaction temperature.]

de solução sólida. Quando tratado a $1100{ }^{\circ} \mathrm{C}$ observa-se a segregação de $\mathrm{Sn}_{2} \mathrm{La}_{2} \mathrm{O}_{7}$.

Analisando-se o padrão de difração das amostras de $\mathrm{SnO}_{2}$ dopadas observa-se que, em todos os casos, os picos apresentam-se alargados em relação aos picos de difração das amostras não dopadas.

A partir dos dados de difração de raios $\mathrm{X}$ observou-se que os valores dos tamanhos médios dos cristalitos das nanopartículas, calculados pelo método de Rietveld [14], das amostras dopadas com Ce, Y e La apresentaram-se bem menores que os valores para a amostra não dopada (Fig. 4a), sugerindo que os dopantes controlam o crescimento das partículas. Os três dopantes apresentaram comportamento semelhante com respeito ao crescimento do grão, sendo que o Y e o La apresentam comportamento idêntico.

Sabe-se que no caso das amostras dopadas com Y e La ocorre segregação de estanatos, isto pode indicar que o Y está no retículo cristalino de forma semelhante ao La, mesmo que o $\mathrm{Sn}_{2} \mathrm{Y}_{2} \mathrm{O}_{7}$ segregue em temperatura inferior, enquanto que o Ce espera-se que este esteja na rede de forma diferente, uma vez que ocorre a segregação do $\mathrm{CeO}_{2}$ ao invés de estanato.

Os efeitos causados pela presença dos cátions das terras raras, na propriedade catalítica das amostras, foram estudados na reação de decomposição do metanol em diferentes temperaturas reacionais, Fig. 5. Os produtos identificados na reação foram o $\mathrm{CO}_{2}, \mathrm{H}_{2} \mathrm{O}$ e $\mathrm{H}_{2}$.

As amostras de $\mathrm{SnO}_{2}$ dopadas e não dopadas, tratadas termicamente a $550{ }^{\circ} \mathrm{C}, 900{ }^{\circ} \mathrm{C}$ e $1100{ }^{\circ} \mathrm{C}$ apresentaram uma atividade catalítica diferenciada. Com o acréscimo da temperatura de calcinação, as amostras apresentaram um decréscimo na conversão do metanol, o que pode estar relacionado com o crescimento do tamanho da partícula, decréscimo da área superficial e a formação da camada de segregação observada na temperatura mais elevada de calcinação $\left(1100{ }^{\circ} \mathrm{C}\right)$. Com a formação de $\mathrm{Sn}_{2} \mathrm{Y}_{2} \mathrm{O}_{7}, \mathrm{Sn}_{2} \mathrm{La}_{2} \mathrm{O}_{7}$ 


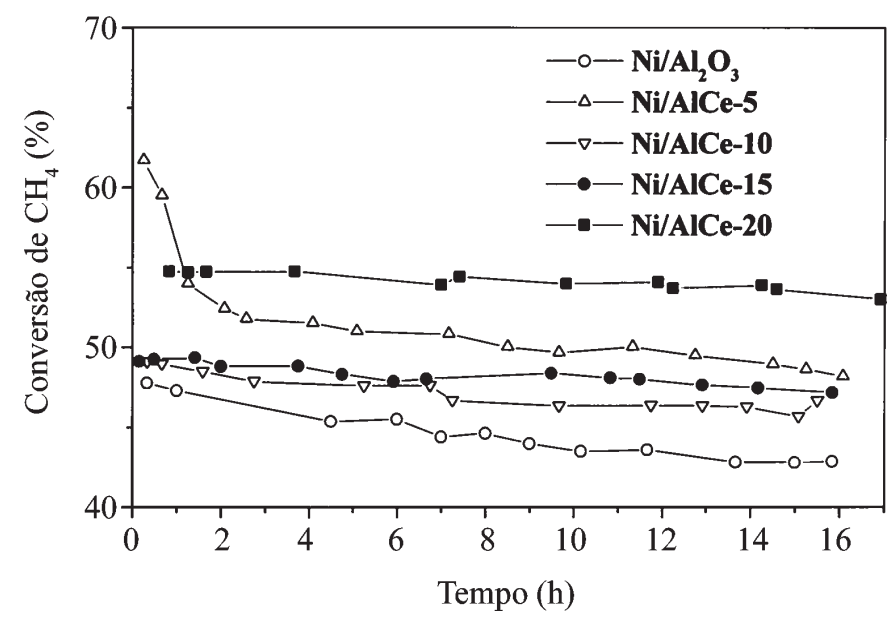

Figura 6: Conversão de metano em função do tempo, para os diferentes catalisadores, ativados em $650{ }^{\circ} \mathrm{C}$ durante $1 \mathrm{~h}$, temperatura reacional de $625^{\circ} \mathrm{C}$, massa de $50 \mathrm{mg}$.

[Figure 6: Methane conversion as a function of time, for the different catalysts activated at $650{ }^{\circ} \mathrm{C}$ during $1 \mathrm{~h}$, reaction temperature of $625^{\circ} \mathrm{C}$, mass $50 \mathrm{mg}$.]

e $\mathrm{Ce}_{2} \mathrm{O}$ na camada externa da partícula para as diferentes amostras, como citado anteriormente, os resultados obtidos indicam que a presença de La e Y promovem o decréscimo na atividade catalítica do $\mathrm{SnO}_{2}$ na reação de decomposição do metanol.

Amostras impregnadas do sistema $\mathrm{Ni} / \gamma-\mathrm{Al}_{2} \mathrm{O}_{3}-\mathrm{CeO}_{2} e$ seus efeitos na reação de reforma do metano

A Fig. 6 apresenta os resultados dos testes catalíticos das amostras, obtidos na reação de reforma do metano com dióxido de carbono. Observa-se que para as amostras contendo $\mathrm{CeO}_{2}$, a conversão do $\mathrm{CH}_{4}$ foi superior a apresentada por $\mathrm{Ni} / \mathrm{Al}_{2} \mathrm{O}_{3}, \mathrm{O}$ que concorda com os maiores valores de dispersão de $\mathrm{Ni}$, observados. No intervalo de tempo de 15 horas de teste catalítico contínuo, é possível observar que a presença de $\mathrm{CeO}_{2}$, na composição do catalisador, proporciona um aumento de atividade e na estabilidade catalítica, sendo esta última, mais pronunciada para as amostras que possuem uma taxa maior de $\mathrm{CeO}_{2}$.

A maior estabilidade catalítica observada para as amostras contendo $\mathrm{CeO}_{2}$, relaciona-se com a menor deposição de coque em tais amostras (DRX e CHN) quando comparadas a $\mathrm{Ni} / \mathrm{Al}_{2} \mathrm{O}_{3}$. As reações de formação de coque, na reforma com $\mathrm{CO}_{2}[15]$ :

$$
\begin{aligned}
& \mathrm{CH}_{4} \leftrightarrow \mathrm{C}+2 \mathrm{H}_{2}, \\
& 2 \mathrm{CO} \leftrightarrow \mathrm{C}+\mathrm{CO}_{2}, \\
& \mathrm{CO}+\mathrm{H}_{2} \leftrightarrow \mathrm{C}+\mathrm{H}_{2} \mathrm{O},
\end{aligned}
$$

e também a reação de hidrogenação de $\mathrm{CO}_{2}$ promovida pelo metal em elevada temperatura:

$$
\mathrm{CO}_{2}+\mathrm{H}_{2} \leftrightarrow \mathrm{CO}+\mathrm{H}_{2} \mathrm{O}
$$

são reações paralelas que podem levar a diferentes seletividades, observadas nos diferentes testes catalíticos.

Tais reações paralelas, ocorreriam com maior facilidade no

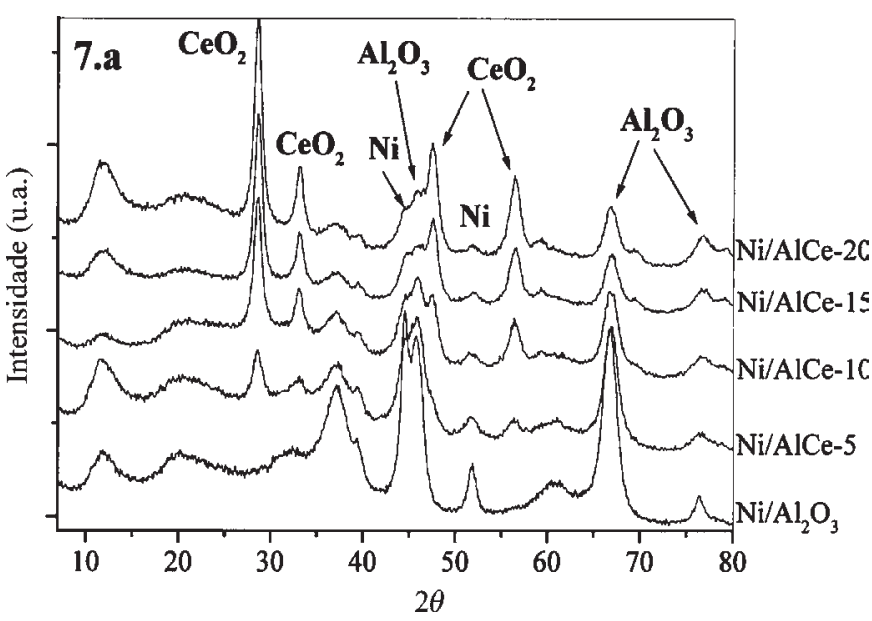

Figura 7: Difratogramas de raios X dos catalisadores Ni/AlCe, antes do teste catalítico.

[Figure 7: XRD patterns of the Ni/AlCe catalysts, before the catalytic test.]

catalisador $\mathrm{Ni} / \mathrm{Al}_{2} \mathrm{O}_{3}$, ocasionando uma maior deposição de coque (equações 1 a 3 ) e um decréscimo na seletividade, por intermédio do consumo de $\mathrm{H}_{2}$,

Para o catalisador $\mathrm{Ni} / \mathrm{CeO}_{2}$, não foi observada conversão do metano, em testes realizados nas mesmas condições reacionais, fato este relacionado com a microestrutura que apresenta esta amostra, comportamento discutido a seguir.

\section{Caracterização microestrutural dos catalisadores}

Os difratogramas de raios $\mathrm{X}$, obtidos após previa ativação em $650{ }^{\circ} \mathrm{C}$, ilustrados na Fig. 7a, mostram a fase cristalina do sistema Ni/AlCe, com o aumento da concentração de $\mathrm{CeO}_{2}$. Fig. 7 ilustra também o alargamento dos picos correspondentes aos planos cristalinos 111 e 200 do Ni metálico, com a adição de $\mathrm{CeO}_{2}$. Esta observação pode estar relacionada com o aumento da dispersão metálica devido à adição de $\mathrm{CeO}_{2}$, o que sugere

Tabela II - Percentagem de carbono determinado por analise elementar (CHN), nos catalisadores depois do processo de reforma do metano.

[Table II - Carbon percentage determinated by the element chemical analysis $(\mathrm{CHN})$, in the catalysts after the methane reforming process.]

Catalisador

C

(\% em massa)

\begin{tabular}{ll}
\hline $\mathrm{Ni} / \mathrm{Al}_{2} \mathrm{O}_{3}$ após ativação & 0,02 \\
\hline $\mathrm{Ni} / \mathrm{Al}_{2} \mathrm{O}_{3}$ após 15 horas de uso a $625^{\circ} \mathrm{C}$ & 30,48 \\
\hline $\mathrm{Ni} / \mathrm{AlCe}-5$ após 15 horas de uso a $625^{\circ} \mathrm{C}$ & 9,52 \\
\hline $\mathrm{Ni} / \mathrm{AlCe}-10$ após 15 horas de uso a $625^{\circ} \mathrm{C}$ & 9,99 \\
\hline $\mathrm{Ni} / \mathrm{AlCe}-20$ após ativação & 0,18 \\
\hline $\mathrm{Ni} / \mathrm{AlCe}-20$ após 15 horas de uso a $625^{\circ} \mathrm{C}$ & 9,86 \\
\hline
\end{tabular}




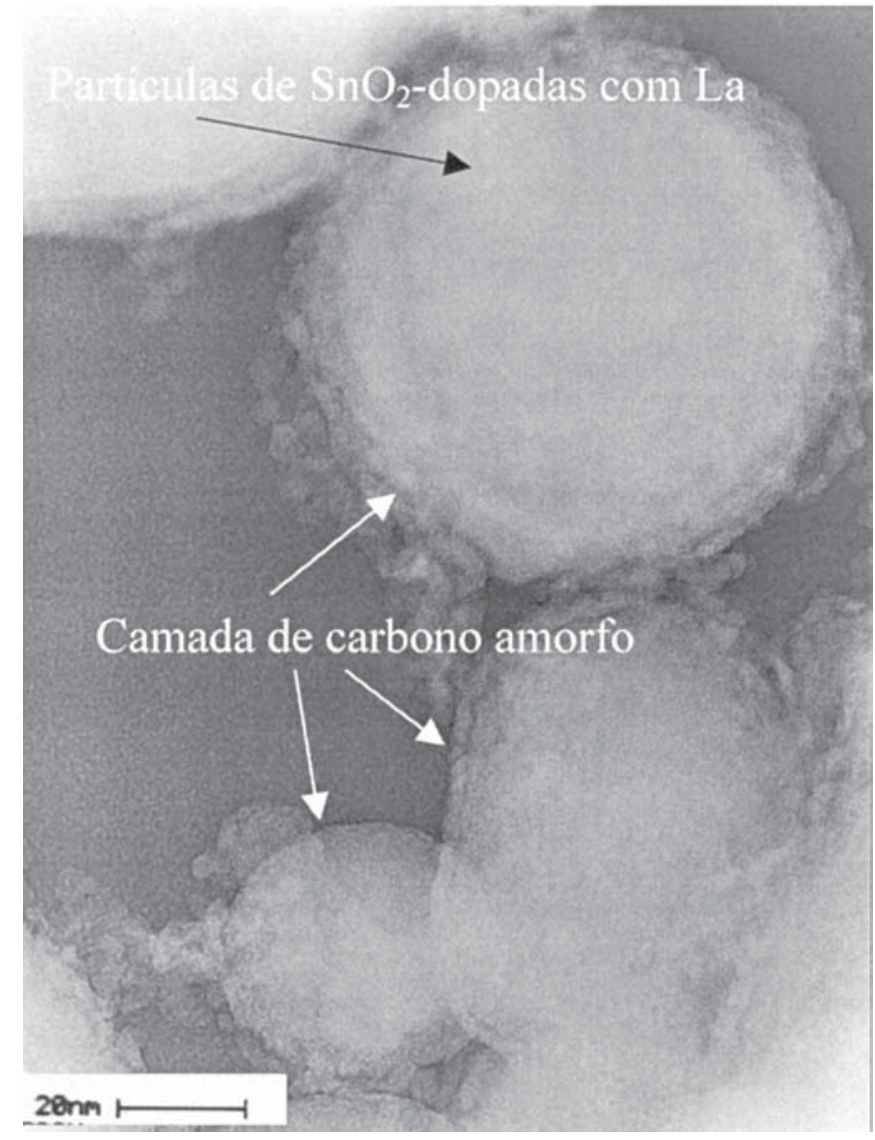

Figura 8: Imagens de campo claro de MET, da amostra de $\mathrm{SnO}_{2}$ dopada com La após o teste catalítico a $450{ }^{\circ} \mathrm{C}$.

[Figure 8: BF-TEM images of the $\mathrm{SnO}_{2}$ doped with La, after the catalytic test at $450^{\circ} \mathrm{C}$.]

uma diminuição do tamanho de cristalito do $\mathrm{Ni}$ [16]:

No presente trabalho não foram determinados os valores de tamanhos de cristalito, devido ao fato de que o plano cristalino 111 do níquel, com maior intensidade, encontra-se sobreposto pelo pico do plano cristalino 400 do $\mathrm{Al}_{2} \mathrm{O}_{3}$, e não permite uma adequada deconvolução do pico 111 do Ni. Contudo, os significativos alargamentos dos picos da fase cristalina do $\mathrm{Ni}$ 111 e principalmente do 200 , sugerem uma diminuição do tamanho de cristalito de $\mathrm{Ni}$, quando é adicionado o $\mathrm{CeO}_{2}$.

\section{Deposição de carbono}

A análise da amostra de $\mathrm{SnO}_{2}$ dopada com La após o processo de reforma do metanol em presença de uma atmosfera de $\mathrm{N}_{2}$, acompanhadas por imagens de campo claro de microscopia eletrônica de transmissão, mostram resíduos de carbono amorfo em volta das partículas nanométricas. Contudo, esse problema pode ser solucionado quando usada uma atmosfera de ar (Fig. 8).

Nas amostras contendo $\mathrm{Ni} / \gamma-\mathrm{Al}_{2} \mathrm{O}_{3}-\mathrm{CeO}_{2}$, foram observado resíduos de carbono ordenado (nanotubos de carbono), que foram mais expressivos na amostras sem dopante $\mathrm{CeO}_{2}$, fato confirmada por intermédio de análise elementar (CHN) presente na Tabela II, que sugere que $\mathrm{CeO}_{2}$ contribui efetivamente na eliminação de resíduos de carbono no catalisador, dificultando

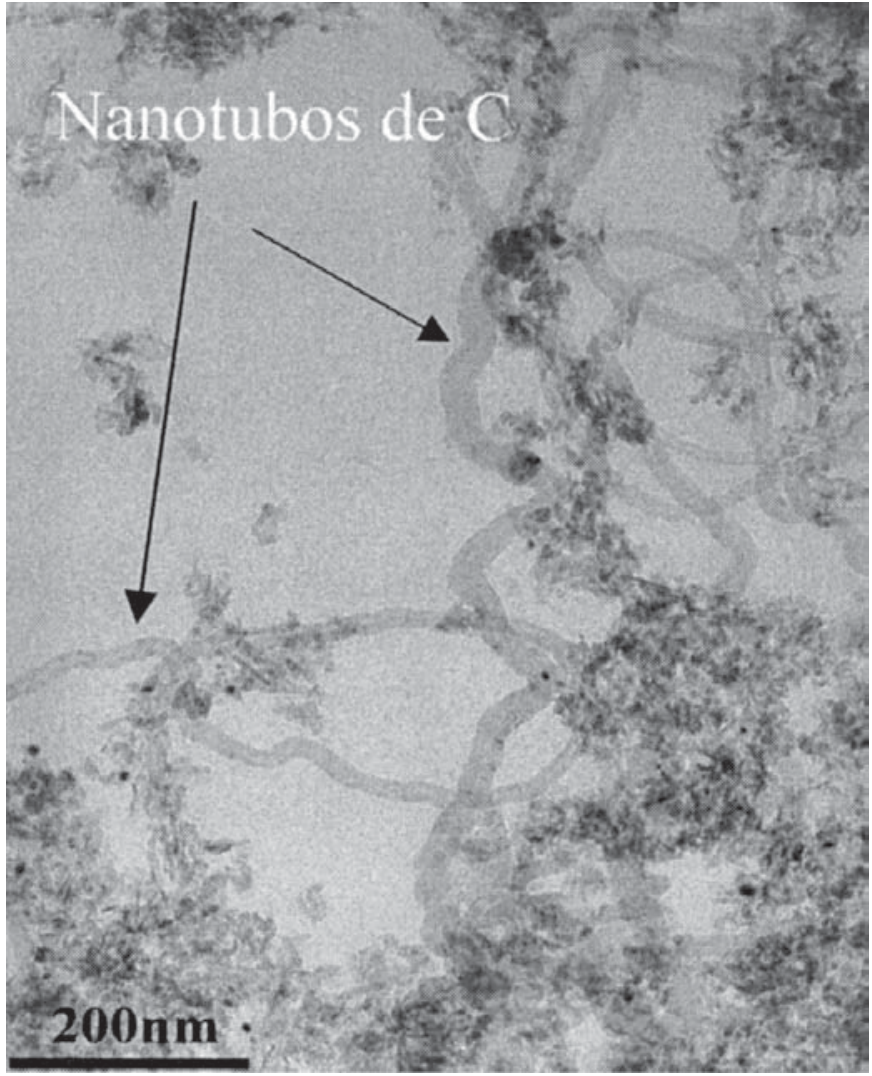

Figura 9: Imagens de campo claro de MET, da amostra $\mathrm{Ni} / \mathrm{Al}_{2} \mathrm{O}_{3}$, após o teste catalítico a $625^{\circ} \mathrm{C}$.

[Figure 9: BF-TEM image of the $\mathrm{Ni}_{1} \mathrm{Al}_{2} \mathrm{O}_{3}$ sample, after the catalytic test at $625^{\circ} \mathrm{C}$.]

a formação dos compostos de elevada massa molecular à base de carbono, responsáveis pela desativação dos catalisadores. O percentual de carbono nas amostras Ni/AlCe, após os teste catalítico, não apresentou variações muito significativas em relação com a concentração de $\mathrm{CeO}_{2}$.

A condensação de carbono amorfo sobre o cristal de $\mathrm{Ni}$, exposto na superfície do catalisador impregnado na alumina, permitiu a formação, inicialmente, de uma camada em torno da partícula de $\mathrm{Ni}$, com subsequente crescimento do nanotubo de carbono [17]. Este processo guia o encapsulamento da partícula metálica e a separação do níquel da superfície do carreador, como ilustra a imagem de MET da amostra $\mathrm{Ni} / \mathrm{Al}_{2} \mathrm{O}_{3}$, após o processo catalítico. A perda da atividade catalítica esta estreitamente relacionada com o fato do bloqueio dos sítios ativos por tubos de carbono, ilustrado na imagem da Fig. 9. Ao contrario do catalisador $\mathrm{Ni} / \mathrm{Al}_{2} \mathrm{O}_{3}$, os catalisadores contendo $\mathrm{CeO}_{2}$, em condições similares, não são igualmente propensos à formação de estruturas de carbono como a amostra de $\mathrm{Ni} / \mathrm{Al}_{2} \mathrm{O}_{3}$.

A resposta catalítica observada na reação de decomposição do metanol e de reforma do metano para as amostras testadas sugere a possibilidade de controlar a seletividade reacional por intermédio da microestrutura e morfologia dos catalisadores.

$\mathrm{O}$ mecanismo que guia a manutenção da estabilidade catalítica dos sítios ativos, no sistema Ni/AlCe, pode estar associado ao caráter oxidante do $\mathrm{CeO}_{2}$ e a sua apreciável 
capacidade de estocar oxigênio para participar dos processos catalíticos, fato diversas vezes descrito [9]. Como consequiência, uma notável contribuição na reatividade catalítica, por intermédio da oxidação e posterior gaseificação das espécies carbonadas, formadas nas reações paralelas ao processo de reforma do metano são descritas.

\section{CONCLUSÕES}

No presente trabalho foram mostradas diferentes formas de preparo de materiais cerâmicos que podem ser usados para obter materiais, com propriedades catalíticas diferentes, que envolvem diferentes tipos de atividade, estabilidade e seletividade catalítica.

$\mathrm{O}$ resultados catalíticos observados pela adição de $\mathrm{CeO}_{2}$ no sistema $\mathrm{Ni} / \gamma-\mathrm{Al}_{2} \mathrm{O}_{3}$, incentivam a obtenção de catalisadores que promovam uma maior estabilidade com controle do coque por intermédio de métodos diferenciados, pois se acredita que a melhor distribuição (homogeneidade) do material resultará em conversões e estabilidade catalíticas superiores aos aqui apresentados.

\section{AGRADECIMENTOS}

Os autores agradecem o suporte financeiro prestado pelas agências de fomento: FAPESP/CEPID, CNPq / PRONEX e CAPES.

\section{REFERENCIAS}

[1] L. L. Figueiredo, F. Ribeiro, Catalise Heterogênea, Fundação Calouste Gulbenkian, (1987).
[2] B. C. Gates, J. R. Katzer, G. C. A. Schuit, Chemistry of Catalytic Processes, McGraw-Hill Book Company, New York, (1979). 464p. p.276.

[3] N. Ichikumi, M. Shirai, Y. Iwasawa, Catal. Today 28 (1996) 49.

[4] Chem. Eng. Mag, Ed.: Nicholas P. Chapey; The Mc GrawHill Companies, Inc., 106, 10 (1999) 70.

[5] R. Psaro, S. Recchia, Catal. Today 41 (1998) 139.

[6] R. Brayner, D. Ciuparu, G. M. Da Cruz, F. Fiévet-Vincent, F. Bozon-Verduraz, Catal. Today 57 (2000) 261.

[7] V. A. Semikolenov, I. I. Llyna, I. L. Simakova, Appl. Catalysis A: General 211 (2001) 91.

[8] A.Trovarelli, Catalysis Rev. 38 (1996) 439.

[9] S. Freni, G. Calogero, S. Cavallaro, J. Power Sources 87 (2000) 28-38

[10] E. R. Leite, N. L. V. Carreño, L. P. S. Santos, J. H. Rangel, L. E. B. Soledade, E. Longo, C. E. M. Campos, F. Lanciotti Jr., P. S. Pizani, J. A. Varela, Appl. Phys. A 73 (2001) 567.

[11] H. Klug, L. Alexander, X-Ray Diffration Procedures, John Willey and Sons (1954).

[12] E. P. Barret, L. G. Joyner, P. P. Halenda, J. Am. Chem. Soc., 73, 1 (1951) 373.

[13] R. A. Young, A. Sakthivel, J. Appl. Crystallogr. 21 (1988) 416.

[14] S. B. Tang, F. L. Qiu, S. J. Lu, Catal. Today 24 (1995) 253.

[15] G. Q. Lu, S. Wang, Appl. Catal. B. Environmental, 19 (1998) 267-277.

[16] S. C. Tsang, J. B. Claridge, M. L. H. Green, Catal. Today 23 (1995) 3.

(Rec. 29/07/02, Ac. 09/09/02) 